\title{
To Buy or not to Buy: Family Dynamics and Children's Consumption
}

\author{
by Julie Evans and Joan Chandler \\ College of St Mark and St John in Plymouth; University of Plymouth
}

\author{
Sociological Research Online, Volume 11, Issue 2, \\ $<$ http://unw. socresonline.org.uk/11/2/evans.htm/> \\ doi:10.5153/sro. 1397
}

Received: 15 Dec 2005 Accepted: 28 Jun 2006 Published: 30 Jun 2006

\begin{abstract}
This article draws on data from a qualitative study of children living in families with either low or high levels of household income and outlines the intrafamilial dynamics that surround young children's relationships to contemporary consumer culture. The motivation for parents to provide their children with particular commodities, how parents prioritised children's requests and the rationale they used to buy or not to buy certain items was much more complex than parents simply 'giving in' to pester power. In the main, parents were making very considered judgements based on a range of factors. Wider social changes were seen as being contributory to new forms of consumption and thus new experiences of childhood which meant parents having to deal with an aspect of their children's lives that was much more problematic than they had experienced in their own childhoods.
\end{abstract}

\section{Keywords: Children, Consumption, Families, Inequalities, Pester Power}

\section{Introduction}

1.1 It could be argued that children today have a different relationship to the world of consumption than their parents, because of the changing nature of family life and because they are targeted as a distinct and new segment of the market. Consequently childhood and consumption have become deeply enmeshed with each other in fundamental ways (Cook 2005), and as such consumption plays an important part in children's lives as consumers themselves and through their influence on parental choices (McNeal, 1998). Some go as far as to argue that: "Children have become conduits from the consumer marketplace into the household, the link between advertisers and the family purse" (Schor, 2004: 11). Others have argued that children have moved from productive contributors to household economies to "objects of more or less conspicuous consumption" (Hood-Williams, 1990: 160). Therefore, it is unsurprising to see the central role consumer goods have come to play in young children's lives and growing interest in its impact on childparent interchange.

1.2 These changes to children's wider social experiences and in particular the interplay between the marketplace, the 'child consumer' and ultimately for younger children, their parents makes for a new social dynamic. This dynamic occurs within the context of growing economic inequality, where the gap between the highest and the lowest incomes has increased over the last three decades (Social Trends 2005). Children and consumption has also been a lively topic in popular debate. Parents are often seen to be 'giving-in' to children's repeated requests; often dubbed 'pester power,' which thereby exacerbates the cycle of want (Carvel 2000). Pester power, or the 'nag factor' which is more commonly called in America (Schor, 2004), is the critical descriptor of the behaviour children use to get parents to buy them the products they want. Schor argues that children are, in fact, training their parents, without them even realising it, and marketers exploit children's pestering and nagging skills to their full potential. Whilst it is unlikely that parents are as passive as Schor appears to be alluding to there is little doubt that children can and do influence parents shopping choices.

1.3 Furthermore, many parents see the rapid pace of change, even in one generation, in relation to their children's relationship to consumer culture. This has resulted in new areas of parenting issues that have to be regularly negotiated and renegotiated. They see their children's lives as being much more pressurised and complex than they remember in their own childhoods and feel that changes in family structures and a shift into a more consumer orientated society have resulted in new kinds of childhood (Prout 2000). 
class processes in shaping social identities and explaining social behaviour" (Crompton, 1996: 113). However, this paper seeks to set children's consumption within a wider class framework. To discuss consumption and the impact it has on individual lives without looking at access to resources simply seems to negate constraints in acquiring consumer goods. For example, differing household structures in terms of the number of parents, levels of employment and levels of income are all factors that impact on both intrafamilial and interfamilial consumption processes. All children growing up within the family are dependent on the distribution of the resources available within the household income. Currently two million children (17.6\%) live in households where there are no adults in work. For Muslim children the figure rises to a third of all children (Census 2001). This has resulted in what Pahl (1984) terms 'work-rich' and 'workpoor' homes and for many families there have been periods of long-term unemployment often followed by short-term casualised low paid jobs. Additionally many homes don't have a male breadwinner and the number of single parent families has tripled, 1 in 4 families are now headed by a lone parent and nearly 9 out of 10 of these lone parents are mothers (Social Trends 2005).

1.5 There seems to be a judgemental edge to and ambiguity in the literature about why parents are motivated to buy particular commodities for their children. It is not just households with lower levels of income where pressures may be felt even in households where there is 'dual income' or higher levels of income there are still dynamics that operate within consumption agendas. Pugh (2002) argues that 'consumption as compensation' has arisen because the commodity becomes a tradable thing which symbolises relationships and palliates anxieties and guilt that parents feel about what may be wrong or lacking in their children's lives. Parents who are 'cash-rich but time poor' are cited as one example of this (Rice, 2000). On the one hand the contemporary focus on consumption diverts attention away from material inequalities. On the other poorer parents are often described, particularly by the better off, as 'lacking control' and prone to 'give in' to children's repeated requests for certain items. Yet Pugh's work highlights there are tensions for parents in both high income and lower income households in dealing with children's wants.

1.6 A key area then within this debate is the increasingly divided society that children encounter, where income distribution is skewed in favour of more affluent households (Stewart, 1992). A substantial minority of children, according to Smith find themselves marginalised and excluded from mainstream material and social wealth, which, arguably results in tension and resentment. Smith (2000) suggests that for many children, particularly those who are disaffected from the education system, aspects of consumer culture give them a sense of identity. He argues that for children on the margins of society the pressures to conform are more acute as their sense of inadequacy is easily awakened, especially if they are not able to participate fully in all areas of social life. Conformity 'may be achieved through personal choice. Those with restricted choices however may find conformity becomes more compelling' (Smith, 2000: 8). Here marginalised children seek recognition and acceptance as well as legitimation, by being equal members of the consumer society. This last point seems to be highly relevant when looking at the dynamics between both parents and children and children and their peers as well as their attitudes and behaviour towards the consumption process per se. There is, for example, a particular need to understand more fully what it means to live in a 'consumer based society' when individuals do not have the resources to participate fully.

1.7 All too often people mistake consumer goods as tangible evidence of an individual's social mobility. For example owning a television was once a symbol of affluence, but nowadays its absence is a sign of poverty (Lunt and Livingstone 1992). A point worth mentioning here is that whilst children may well end up with the same item or commodity the unequal distribution of resources in households means that the way in which those items are finally purchased varies significantly in terms of planning, method of payment, time and eventual acquisition (Berhau 2000 cited Pugh, 2004). In short, wider social changes have had a direct impact on both children's lives as social actors and consumers and ultimately on parents who have to manage children's wants and needs within the consumption arena.

1.8 Thus, the complexities of the intra-familial dynamics of the consumption process often get lost in a particularly negative discourse in which, much of the right wing press often blame parents for feeding children's cravings for certain consumer goods.

1.9 This paper aims to explore the changing nature of consumption and the discourses surrounding this aspect of the sociology of consumption literature in relation to notions of both contemporary family life and equally contemporary notions of parenting. Looking at what motivates parents to buy or not to buy particular items is also of relevance in trying to understand the intrafamilial dynamics of consumption as is the 'classed' dimensions of the consumption process per se. There is also a need to highlight the interplay between consumption and the role of the 'good' parent. In particular we are keen to move the discussion away from parents being seen as irresponsible by giving in to children's demands (Furnham, 2000), and to illustrate the complexities of the dynamics that exist within families in relation to children and consumption. 
2.1 The paper will draw on data collected from a study undertaken with forty-five children ranging from 7-11 years-of-age: twenty-four girls and twenty-one boys. A range of methods were used with the children, for example, diaries which they completed over a weekend period prior to the researcher going into the school; small group discussions; and an activity whereby the children had to rewrite the end of a story in which the central characters discussed how they might negotiate with adults to obtain commodities such as toys, games and clothing. Within the UK, children across all social class groups are found to have the greatest influence on parents' shopping behaviour between the ages of $5-11$ (Mintel 1991, cited Gunter and Furnham, 1998). What large studies such as the Mintel study often do not demonstrate however, is the localised and the particular within the context of the intrafamilial dynamics of consumption. This study wanted to try and access both children and parents perspectives on household consumption processes to highlight some of the minutiae of the adult and child interaction(s) within the consumption arena.

2.2 The role that parents occupy within the children's consumer biographies is essential in fully understanding both the children's experiences of consumption as well as its effects on the family unit given the economic dependency of children aged 7-11. How parents prioritise and manage the many demands placed on familial household budgets was seen to be central in understanding the dynamics that exist between the children, their parents and children's friendship groups in relation to consumption. Thus, nineteen parents (fourteen mothers and five fathers) aged between twenty-eight and forty-seven were individually mostly interviewed in their homes, with two fathers interviewed in their workplace. Children were recruited through schools and parents were recruited via the consent form they had completed for their child to participate in the study. From this just under half the parents $(42 \%)$ of the children who participated volunteered to be part in the study.

2.3 While much has been written about the effects of social class reproduction and poverty on families who have very limited incomes or who are reliant on state benefits, there has been little research into the effects (if any) the consumption process has on their lives. In order to access the inequalities of the consumption process this study focussed on two areas in the Southwest of England based on deprivation scores at neighbourhood level within the area (Nelder \& Maconachie, 1997). Based on indices of multiple deprivation data, the two areas chosen had either a very low deprivation indicator on either a single or a combined measure or a very high score.

\section{How do parents prioritise children's requests?}

3.1 One important dimension of children's consumption is understanding how parents prioritise children's requests. In the negotiation processes that occur between children and their parents to buy particular commodities, parents in this study responded to requests based on a range of factors. Clearly household economics irrespective of the level of household income, places a limit as to how much money parents may have available or how much money they are prepared to spend to purchase particular items. A key focus of the parental interviews was to identify how they 'managed' children's requests for consumer goods within their overall household budget. What was striking about the data was not that parents were 'irresponsible' or unaware of the issues regarding this aspect of their children's lives, but that they were going to inordinate lengths to think through and justify buying or not buying particular items. Although it was generally the children that drove the process, parents listened to children's requests and vetted them broadly around the following criteria:

i. Value for money;

ii. Education;

iii. Use-value. Parents wanted to be sure that children would not get bored with the item relatively quickly. They did not want to be buying things on a whim.

iv. The more persistent children were in requesting a particular item, the more likely parents would eventually take the request seriously. Parents felt that children asked for things all the time and on many occasions they would forget about an item if the parent did not pick up on it straight away. This is an interesting dynamic because, when asked, the children were very aware and very adept in realising that in order to get something you often had to repeatedly ask for that item.

v. A few parents mentioned the fun factor of certain items. There were some parents who said that in the end they were children and to an extent you had to go along with fads. In essence, some parents felt that part of 'childhood' is to be involved with particular forms of popular culture.

3.2 A strong theme to emerge from the parental data was the notion that the stronger the educational dimension of particular commodities the more likely parents were to buy them. All parents spoke of the need for children to have certain educational toys as a must to ensure success within their formal education and those in the less affluent area spoke of needing to have these items to ensue that their children did not get left behind in the education system. 
3.3 Seiter (1993) argues that children's consumption habits become the focus for an anxiety that previously centred on working-class consumer habits in the late nineteenth and early twentieth century. Self-control and decadence are all according to Seiter the language used when discussing products such as mass market toys sold in large scale 'Toys $r$ Us' type stores. Educational and quality toys escape this labelling as they are seen to be aspirational for future development. Brusdal (2005) describes the dichotomous thinking whereby all things that are 'educational' are seen as inherently good and all things that may be seen as just 'superficial' are evidence of the negative pervasiveness of consumption into children's lives. This study strongly supports such a dichotomy.

Bev. Well they tend to tell us what they like and you know we sort of decide whether it's appropriate for the age really. Um it's like my eldest daughter got her own computer and that but she's coming up for GCSE work so we thought that would be a good thing, plus Pia is doing it over primary school so buying that isn't... what can I say...it's an educational need then. If it's educational then we do buy loads of stuff like that but obviously we buy the Barbie's for Paige she has all that but then she plays hours and they reckon they learn through play anyway don't they so that's important?

(Parent - less affluent area)

Liz: ...it depends how badly they want it um the more educational the better Mia's been after a keyboard for a while so we decided to get her one for her birthday this year. That's fairly educational she likes music she enjoys music at school and it's not one of these five-minute fads...you know um yeah the more educational the better.

(Parent less affluent area)

3.4 In this study, social class was not of significance in terms of parents' ultimate decision to buy particular commodities. Parents from the more affluent area gave the same rationale as the parents in the less affluent area for buying certain items and as we can see from James' response below shows the middle classes also justify their decisions within a discourse of education. For James, buying the latest 'fad' toy, was based on the merits of the skills required to play the game as being equivalent to skills required in the National Curriculum.

June: Yeah I mean it's like um computer games if they had educational value it'd be at least twice more likely to get them than if it was just for entertainment.

(Parent - more affluent area)

Stephanie: No we don't use it (the computer) for games they've got to use them for writing or something a bit educational like S.A.T. tests.

(Parent - more affluent area)

James: I mean they've had, they've had a lot of good fun and entertainment out of it and as I say there's a certain amount of educational value and there's the social skills of just swapping and bartering and doing all that so although people sort of slam it it's actually quite good in many ways it's quite good. You could actually link it up to the curriculum if you want to for all the skills that it might teach you and you could probably put it forward as an educational toy eventually if you wanted to.

(Parent - more affluent area)

\section{Looking back and looking forward}

4.1 Another strong theme that emerged was how much parents reflected back on their own childhood for their decisions about their children. This intra-generational 'flipping' resulted in some very rich narratives as to how much parents' earlier experiences were shaping their adult lives and the lives of their children. Martens et al. (2004) suggest that this reflection by parents' on their memories of childhood, lies at the heart of children's consumption. Childhoods of the past were active in the present and the childhood values of adults shaped parenting practice. As Giddens suggests 'the self forms a trajectory of development from the past to the anticipated future' (1991: 72) in which the reworking of childhood holds a central place. In the interviews parents were very reflective in the negotiations about purchases and were using their recollected experience of childhood to parent their own children.

Sally: I always had a lot of toys Christmas, birthdays I always had loads and then my parents split up so then I had double like so I feel I want to give that to her as well. I know how excited I was Christmas and birthdays and it's, when she comes down in the mornings and sees the presents it's like wow you know and that's how I was and that's how I want her to be.

(Parent - more affluent area) 
Jenny: When I was younger there wasn't a lot of money around and...I can remember my mother having to buy second-hand hand toys for us which she didn't have any other choice but she felt really bad buying second [hand] .... And I think...I've just gone totally the other way. Whereas if I can get it for them they can have it I'm sorting of making up for what I never had.

(Parent - less affluent area)

4.2 Parents were exercised by the topic and in the main saw the issues surrounding children's consumption practices as being much more complex and pressurised than they had experienced in their own childhoods. This confirms other studies (Jackson et al, 2000 and Thomson et al 2000). While there is a danger of lapsing into nostalgia in looking back in time, there is enough evidence to indicate, that as far as parents are concerned, there had been a significant shift in children's consumption experiences over the last two or three decades. This issue came up repeatedly in parental interviews in both economic areas:

Mike: Oh it is nowadays isn't it it's not like when we was kids like you got what you got that's what you had like, but nowadays everybody has to keep up with the fashions and with the new toys that's out. All this computer game stuff and everything like you know.

(Parent - less affluent area)

June: I think you look for more things to occupy them to keep them busy indoors but I think as well they are just not content with the sort of pastimes we had like...painting and colouring-in and well simple things like playing cards.

(Parent - more affluent area)

\section{Risky childhoods?}

5.1 About one quarter of the parents referred to the notion of how entertainment and leisure time has had to change for children. These changes were reflected in parents' perceptions that the world had become a much riskier place for children. In the minds of the parents children have had to retreat from the public arena to the private arena with home becoming a panoptical space where children could be 'supervised' at all times. James et al. (1998) assert children are arguably more hemmed in by surveillance and social regulation than ever before. In line with other literature in the area, amusements and leisure time have also changed, to offer children 'safer spaces' in which to 'entertain' themselves (Livingstone, 1998). Homes, and more specifically children's bedrooms, furnished with media and technological entertainment, Livingstone argues, offers children a diverting, technological rich alternative to the perceived risks of the outside world. The parents interviewed in this research reinforced the view and many reported there had been a big shift in children participating in home entertainment leisure activities, for example, watching more television, increased use of videos and music systems. All these activities were seen as a 'safer leisure option:' which have all resulted in children's changing experiences in how they use their leisure time and the types of consumer goods they use to entertain themselves. However, the emphasis on home-centred leisure among the parent reflected in the diaries that children completed about their leisure activities, where many children detailed 'playing outside or playing in the park' with their friends as a leisure activity they had undertaken in the weekend period.

5.2 The risk issue was of concern in the affluent and poorer area. Both groups of parents brought similar issues up surrounding this aspect of the research. For example, June (parent - more affluent area) commented:

June: Um I think we used to play outside with other children a lot more we used to go off for hours and if we were indoors we played with each other...more or we played on our own for hours

Researcher: So that's...your children don't go outside as much or they do...?

June: No I think as they've got older as they get to sort of year 6, 7 I give them more freedom certainly not as young children no. I suppose when we were 7 or 8 we were allowed the freedom of the locality, which they wouldn't be now.

Researcher: Because?

June: Well just because there's more traffic there's more sort of stranger danger um and there's not other children out there playing you know there's always lots of other children that they.... and of course now there's not and I think that's the biggest danger is children out on their own I think if they are in groups they are sort of a lot safer.

5.3 Parents from the least affluent area also expressed similar concerns about safety and the fears that some of them felt in allowing children to be out playing unsupervised or for long periods of time. These fears were not just about 'stranger danger' but also the sorts of things children would be doing if they were left to play outside (particularly at night): 
Mike: I used to like playing in the woods quite a lot when I was little but you know it's not safe for them to do nowadays whereas I think they're more orientated sat in front of the box nowadays...I know Sam is coming up for 12 but I still worry. I say to him be in at a time and if he's a bit late I think oh you know 'cos it's not very safe nowadays...I do worry who he hangs around with you know some new friends I try to talk to them find out what they are like you know 'cos don't want him to get in to trouble or whatever like.

(Parent - less affluent area)

\section{Parents and 'peer pressure'}

6.1 As children age, they expand their social relationships beyond their immediate family environment, and the peer group culture becomes important to children and young people to enable them to gain a sense of belonging, to shape their identity and interact with other children (Corsaro, 1998; Erikson, 1963). The parents interviewed were keenly aware of peer pressure. They saw it as the biggest influence on children's wants and felt that this aspect of children's lives was much more influential than they had remembered it from when they were children. Parents were aware of peer pressure arguments as a rationale for responding to children's requests but, although they wanted to resist giving in, ultimately felt that they needed to go along with it to ensure their children did not feel marginalised:

Bev. I think, I think that at this time I mean when I was younger I didn't feel there was any pressure but I think now there's like magazines and you must do that....and I think there is a lot of pressure at school now.

(Parent - less affluent area)

Lisa: I never had a new bike you know being the last one um and I don't feel that I went without I don't remember being miffed or cross that I went without but then there wasn't the advertising and there wasn't the peer pressure... but I do feel at times that I would like to do things for them because they are under peer pressure I appreciate more what they are going through.

(Parent - less affluent area)

6.2 It is not just toys and possessions that were important within younger children's friendship groups, clothing and fashion were also significant. Previous research has noted that appearance and clothes form a common focus for 'teasing' (Hill and Tisdall 1997). Children use name calling and insults to exclude or marginalise others, often it seems without any particular rationale for doing so. However the effects, according to Butler and Williamson can be deep and lasting, "Name-calling grinds away. What's supposed to happen is you ignore them it's supposed to wear off, but it never wears off." (1996: 54). Hill and Tisdall go on to assert that in order for children to conform to social norms of appearance and dress, children subsequently adopt a range of strategies to minimise differences, such as dressing in a particular style or throwing away elements of packed lunches that may draw disapproval. Children in this study were very aware of what the 'right' clothing would be and automatically made references to charity shop clothing:

Max: Don't get tooken the mick out of 'cos they're in the fashion and people see they dress smartly. (Child aged 10 less affluent area)

Sam: 'cos like you'd get stuff from Oxfam or something they'd take the mick. (Child aged 11 less affluent area)

Max: There's a girl in our class she wears like charity things.

Researcher: Do you think people make a difference because of that.

Sam: Yeah 'cos they take the mick don't they?

Adam and Joe: Yeah!!

6.3 Interestingly, the subject of shopping in charity shops never emerged from discussions within the more affluent area. Middleton et al. (1994) remind us that children use clothes as a means of making judgements about other children and these are usually enveloped within the wider discourses of poverty and stigma. This results in children having to endure verbal abuse, also a finding of this study. Peer pressure around consumption appeared more sharply focussed for the children living in the least affluent area. This may explain why other studies have reported on the tremendous pressure parents in lower income households face in ensuring children have the 'correct' signifiers of fashion (Middleton et al., 1994; Kempson et al, 1994; Pugh 2004; Power, 2005). However, the findings from the parents in this study, from all social class groups, confirm that they were acutely aware of wanting their children to 'fit-in.' In the following example, Catherine was more anxious about her child 'fitting in' than the child themselves:

Catherine: I think if you don't fit in you get left out of the crowd and I want her to be part of the 
crowd if you know what I mean.

Researcher: Right but she obviously doesn't feel that?

Catherine: Not overly no. I push it more than she wants it really.

(Parent - more affluent area)

6.4 In the following interview, Gina was vocal about not buying certain games or toys just because they were in fashion. However, she reported that after a long battle she conceded in allowing her child to have some Pokemon cards which was a 'fad' game that was circulating at the time:

Researcher: Is that something that you probably wouldn't have bought?

Gina: Oh definitely! There's no way l'd have bought that.

Researcher: Right so what made you kind of give in to that or say yeah okay?

Gina: Because everybody's got them and you don't want your child to be different.

(Parent - more affluent area)

Ben (aged 8), Gina's son commented in his discussion with me that:

'I got teased first when the Pokemon cards came out um and everyone else had them and I was the only boy (laughs nervously) who didn't have any Pokemon cards.'

Ben told the researcher that he could not have the cards because his mum did not like them, when asked why his mother did not like them Ben replied, '... because she thinks it's stealing children's money.'

6.5 This was a family from the more affluent area and the result of Gina's refusal to buy Ben some Pokemon cards meant that he was the only boy in his class who did not have any and thus was unable to participate at break times when his friends were swapping and playing with the cards. Both parents had reflected carefully on the issues and as can be seen from Gina's comments, ultimately Ben's marginalisation was one step too far. The father ultimately went and purchased the cards. This pressure that directly (in the child's case) or indirectly (in the parents case) was being viewed in different ways within the familial home. This was a good example of the high levels of discussion and negotiation within the familial home concerning consumer items. It impacted on all of the family members albeit in different ways, This was not a decision that was taken lightly, but was indicative of the pressures felt by parents to ensure their child's inclusion into wider social networks.

6.6 From the children's perspectives the younger children were talking about wanting to be like their friends, which offered evidence of the power of peer group opinion in ensuring the felt a sense of 'fitting-in.' Ruth, aged 7 from a less affluent area says:

Ruth: I can remember once I wanted to get these new platform boots people call them space boots but my mum said l'd be able to get 'em next time it was my birthday.

Researcher: Why did you really want those?

Ruth: Because my friends and all have got 'em.

Researcher: And why is it important for you to have them?

Ruth: Just so I can be like part of my friends.

Britney (aged 8, more affluent area) when asked about the types of clothes she likes to wear replies:

Britney: Because if it's similar, [to her friends] if it's similar then like, like me and Kerrie

keeps on saying we look like we're twins and we find that quite good.

Again with the older children in the study, friends were a major influence on the types of clothes they would buy. Tamara and Tracy both aged 10 from a less affluent area:

Researcher: Um how do you decide what things you want to buy?

Tamara: My friends!

Tracy: Yeah what I like it's not really my friends it's just what I decide to have it's not no one else 'cos sometimes people copy me and sometimes I copy them.

6.7Certainly whilst working with the children over a period of time and listening to the many conversations that took place, although not often explicitly stated, there was this strong theme of children wanting to belong and to fit in. It seemed to be part of a particular childhood culture. For adults it could be argued that we too want all of those things and as adults age, society and personal choice offers us the autonomy to choose where we would like to fit in. For children however they are not afforded such agency. Children often lack the maturity that for many, age brings and younger children are not always able to make many decisions without adult supervision. Certainly within this study both many parents and children alike were acutely aware that they wanted to 'fit in' with their peers. Peer pressure was operating in subtle and 


\section{Parental roles and children's consumption}

7.1 Having discussed how parents managed children's requests for consumer goods we want to briefly outline who does what in terms of parental roles and children's consumption. In terms of familial roles, changes in household structure resulted in significant shifts as to how the consumption process was managed. Within the literature there is generally a dearth of material which looks specifically at gender roles and the intrafamilial dynamics of consumption. The younger the child under discussion then clearly the context for the discussion has to be family based (see Power, 2005; Pugh, 2004; Chin, 2001; Middleton et al. 1994; Kempson, 1994) but the minutiae as to who does what in different household forms has yet to be fully explored. The data from this study indicates that where there were two parents in the household, the physical process of 'doing' consumption could be constructed as being stereotypically gendered; men adopting the role of provider and women as that of consumer i.e. physically buying the items. As the data below demonstrates mothers generally cast fathers in the role of not capable of buying the right things or of wasting money:

Sally: Yeah, I do everything at Christmas he'll come in with me but I know what I'm going in to get which he's quite happy about really (laughs).

Researcher: Are you happy about that?

Sally: I don't mind yeah he'd probably come home with something totally useless.

(Parent - more affluent area)

7.2 Even where parents were living in separate households, the majority of mothers were still co-ordinating the present list. In the following example Sarah was giving a list to the children's father to ensure the right items were being bought:

Researcher: How do you decide who will buy what?

Sarah: To be honest I give them [children] a list, 'cos Ellie (youngest child) persuaded him to buy her these schools shoes once and they were just not suitable, ridiculous... and they didn't last five minutes! So now I send them with a list and then we both know what we're doing, it's easier that way.

(Parent - less affluent area)

7.3 Many mothers felt that they were better placed to know what the children wanted. Interestingly, on the last point, where there was a mother and father living together it was the mother who did most of the organising and buying of material goods. However, the fathers in the sample who were lone parent took on all the roles that women were occupying in terms of organising Christmas presents, planning ahead to maximise money and buying at sale times when toys and games accrued favourable discounts.

Mike: I'll have put money back each week or else just buy each item each week. You know buy one for one week and one for the other the other week you know it's like September time I've got to start getting ready for Christmas

(Parent - less affluent area)

7.4 The gendered dimensions of how parents managed children's consumption has highlighted some key points for further discussion and reflection. Consumption, and what non-resident parents were buying for children was in many households both a concern and a source of tension. Managing consumer culture is a key aspect of contemporary parenting and as we have said earlier the mechanics of the intrafamilial dynamics of children's consumer culture with respect to gender (and class and ethnicity) across different household forms is a void that needs filling with further empirical study.

\section{Consumption and the 'good' parent}

8.1 Throughout the interviews there was evidence that parents regarded providing their children with the commodities and symbols of contemporary popular culture as indicative of 'good' parenting. This seemed to be highlighted by the significance of presents at Christmas and birthdays. In the least affluent area some parents had already started to buy items for Christmas in the summer and were going to inordinate lengths, planning and budgeting to ensure children were not disappointed.

Sharon: Um last Christmas wasn't bad I only went 70 quid in to debt last year I managed to like keep pennies back and save but the Christmas before I went in to 250 pound in to debt 'cos they wanted bikes.

(Parent - less affluent area)

Jill: No I phoned made numerous phone calls used to go in every Saturday (laughs) I can't 
believe I did it. Her grandmother was doing the same as well... I just had to in the end I had to get it for her you know... because she'd asked for that specifically for Christmas and I suppose that I thought I've just got to do that if that's the only thing she wants for Christmas. (Parent - more affluent area)

Cross (2004) argues that our romantic view of childhood as a time of 'wondrous innocence' serves commercial interests and is promoted through consumer culture. Parents thus enjoy the immediacy of the enjoyment and 'wonder' of their children through gifts they are offering.

8.2 In this context some children receive increasingly costly presents which arguably endorse the importance of material possessions in their lives. For parents also, being able to provide children with the presents that they aspire to, is all part of what Belk and Coon (1993) suggest is the agapic (unselfish) love paradigm. Here unselfish gift- giving has expressive significance and carries no expectation of reciprocal obligation. Providing children with symbols at particular holidays and festivals has undoubtedly become central to a contemporary notion of childhood and this takes us into discourses of what it means to be a parent and to be able to provide your children with popular symbols of consumerism. Other studies also confirm that parents on limited incomes demonstrated the importance of giving children 'a happy time at Christmas' or ensuring they 'fitted in' with their peers was more important than avoiding debt and buying essential items for themselves (Kempson et al 1994; Power 2005).

8.3 It is argued that children also learn that the withholding of a gift may be a withholding of love, so, as they develop they conflate the giving of material possessions with the giving of love (Isaacs 1935). In the interviews presents appeared to be both significant and central in the children's lives too. From the children's perspectives there was evidence that they were associating levels of material possessions with parental love, Mel (aged 10) (from the less affluent area) explicitly said this, when asked the question why some children get more things than other children she replied; "because they love them better." Lila (aged 11 - more affluent area) too, seems to be conflating material possessions with 'love:'

Lila: My mum gets like really nice clothes from like 'Next' and all that...well they say oh you're lucky you've got really nice parents who will spend lots of money on you.

8.4 The following discussion between a group of four 8 year-olds from the more affluent area were relating material possessions as evidence of people caring for you:

Becca: You wouldn't care because no-one cared about you.

Researcher: Is that what you think that if you get lots of things people care about you?

Tom: Doesn't really make a difference but some people do think that people don't care about them if they don't give them lots of things.

Perhaps Belk (1995) is right to suggest that gift giving is enveloped within an expression of love and emotional symbolism. In some cases parents went to great lengths to plan ahead and ensure their children could have at least some of the things they had requested for birthdays or Christmas with gifts that matched those of their friends. As Jill (Parent - more affluent area) suggested, 'All their friends have got it and you think well why shouldn't mine have it, I suppose. '

\section{Concluding discussion}

9.1 It has been suggested in this paper that changing family structures, combined with a shift in to a more consumer based society, have arguably, all resulted in changing times for many children. Those working in the Sociology of Childhood Studies have acknowledged that, "the diversification of children's lives, for example in terms of their family situation, the rise of consumerism with its heightened expectation of choice...the diffusion of democratic norms all these are creating new kinds of childhood and new varieties of children" (Prout, 2000: 7).

9.2 These changes will have consequences for all aspects of young people's lives and in particular their relationships to consumer culture. Some go as far as to argue that understanding how children learn to consume offers insights into contemporary childhoods as well the role of consumption in social change (Martens et al. 2004). Clearly there are some deep-rooted motivations for parents to go to inordinate lengths to ensure their children have certain commodities and symbols of current fashions and trends. This seems not to be just about 'conspicuous consumption' but reflects much more complex and meaningful aspects of the parent child relationship. There is a need to delve more deeply into the discourses that parents and children draw on in order to give a richer and more meaningful profile of both parents and children's attitudes and their beliefs about the world of consumer goods.

9.3 The evidence from this research supports the argument that families are prioritising children's consumer needs over other household expenses to ensure that their children can accumulate the accoutrements of 
modern day living. It also provides a wider understanding of families' experiences of living in a society that is materially divided.

9.4 Parents in this research described how they worked hard to maintain a balance between providing children with the items that they wanted whilst trying to set limits that they felt were appropriate to their individual circumstances. The importance of children realising that they cannot necessarily have everything that they wanted was something that many parents commented on. Parents, it seems were engaging with and reflecting on their own motivations as well as the stimulus created by advertisers and marketers. As can be seen from the above data, resisting the fads and the crazes, results eventually in their children being stigmatised or marginalised on the basis of not being able to join in activities with other children. In these they faced difficult decisions in trying to steer a path through the consumer based society in which we live. To give into children because of peer pressure is a decision that parents appear to feel very uncomfortable about making. Yet to deny their children signifiers of peer inclusion is to risk their child being marginalised and for the majority of parents in this study that was a risk that was ultimately too great to take.

9.5 Parents who are particularly averse to following trends and 'giving in', all gave examples of reversing their initial decisions once they could see that the child was not going to give up on the request. Equally, parents who initially say no, not because of social or political reasons, but because of financial reasons, ultimately relent because as 'good parents' they strive to buy the products at all costs. Their reasons for bowing to children's 'pestering' are often negatively portrayed in the media but parents in this research were preoccupied in wanting their children to have the best chances of social and educational success. It appears that parents realise in order to do this children need a currency to trade with in their academic and social lives. That currency it could be argued, for children, has become material possessions and consumer goods.

\section{Acknowledgements}

The authors would like to thank the editors and reviewers for their helpful comments on an earlier draft of this paper.

\section{References}

BELK, R. and COON GS. (1993) Giving as Agapic Love: An Alternative to the Exchange Paradigm Based on Dating Experiences. Journal of Consumer Research Vol. 20 December 1993 pp 393-417.

BELK, R. (1995) Studies in the new consumer behaviour. in Acknowledging consumption: a review of new studies. D. Miller. London: Routledge.

BERHAU, P (2000) 'Class and the Experience of Consumers: A Study of Practices of Acquisition' unpublished dissertation, Temple University in Pugh, Allison J (2004) 'Windfall Child Rearing: Low Income Care and Consumption.' Journal of Consumer Culture Vol. 4 (2) pp229-249. London: Sage

BRUSDAL, R. (2005) 'Good and bad consumption: Parents and children's consumption' Paper presented Childhoods 2005:Children and Youth in Emerging and Transforming Societies Conference. University of Oslo

CARVEL, J. (2000) TV Ads. 'have little effect' on children. The Guardian Saturday November 11 p.7.

CENSUS (2001) 'Children'- http://www.statistics.gov.uk/census2001/census2001.asp

Accessed September 242005

CHIN, E. (2001) Purchasing Power: Black Kids and American Consumer Culture University of Minnesota Press.

COOK, D. (2005) The Dichotomous Child in and of Commercial Culture. Childhood Vol. 12 (2) p155-159

CORSARO, W. (1998) The Sociology of Childhood . London: Pine Forge Press.

CROMPTON, R. (1996) 'Consumption and Class Analysis' in Consumption Matters. S. Edgell, et al. (Eds.) Oxford: Blackwell Publishers.

CROSS, G. (2004) Wondrous Innocence: Print Advertising and the Origins of Permissive Child Rearing in the US. Journal of Consumer Culture Vol. (4) pp183-201. London: Sage

ERIKSON, E. (1963) Childhood and society. New York: Norton \& Co. 
FURNHAM, A. (2000) in TV Ads. 'have little effect' on children by John Carvel The Guardian November 11 2000 p. 7

GIDDENS, A. (1991) Modernity and Self-Identity: Self and Society in the late modern age. Cambridge: Polity Press.

GUNTER, B AND FURNHAM, A. (1998) Children as Consumers: A Psychological Analysis of the Young People's Market. London: Routledge.

HILL, M. AND TISDALL, K. (1997) Children and Society. London: Longman.

HOOD-WILLIAMS, J. (1990) Patriarchy for Children: On the stability of Power relations in Children's lives. Childhood, Youth and Social Change. Chisolm et al. London: Falmer Press.

ISAACS, S. (1935) "Symposium on property and possessiveness." Medical Psychology 15 69-78.

JACKSON, S. SCOTT, S AND BACKETT-MILBURN, K. (2000) Remembering, rationalising and reflecting on risk: how parents' childhood memories features in accounts of risk to their children. BSA 'Making Time/Marking Time', University of York.

JAMES, A. JENKS, C AND PROUT, A. (1998) Theorising Childhood. Oxford: Polity Press

KEMPSON, E. BRYSON, A AND ROWLINGSON, K. (1994) Hard Times: How Poor Families Make Ends Meet. London: Policy studies Institute.

LIVINGSTONE, S. (1998) Mediated Childhoods: a comparative approach to young people's changing media environment in Europe. European Journal of Communication (13) 4, 435-56.

LUNT, P. AND LIVINGSTONE, S. (1992) Mass consumption \& personal identity. London: OU Press.

MARTENS, L., SOUTHERTON, D., and SCOTT, S. (2004) Bringing Children (and Parents) into the Sociology of Consumption. Journal of Consumer Culture Vol. 4 (2) pp155-182. London: Sage

MCNEAL, J. (1998) "Tapping the three kids' market." American Demographics 20 (April): pp37-41.

MIDDLETON, S., ASHWORTH, K. WALKER, R. (1994) Family Fortunes: Pressures on parents and children in the 1990s. London: Child Poverty Action Group.

NELDER, R. AND MACHONACIE, M. (1997) Deprivation Scores at Neighbourhood Level within Plymouth City. Public Health Team South \& West Devon Health Authority.

PAHL, R. (1984) Divisions of Labour . Oxford: Blackwell Publishers.

POWER, E. (2005) The Unfreedom of Being Other: Canadian Lone Mothers' Experiences of Poverty and Life on the Cheque. Sociology Vol. 39 (4) p643-660

PROUT, A. (2000) Opening Address. Children: Making their future? Research and Policy for the 21st Century. London (Final Conference ESRC 5-16 research programme).

PUGH, A. (2002) From "Compensation" to "Childhood Wonder": Why Parents Buy. Working Paper No 39. Centre for Working Families, University of California Berkeley

PUGH, A. (2004) 'Windfall Child Rearing: Low Income Care and Consumption.' Journal of Consumer Culture Vol. 4 (2) pp229-249. London: Sage

RICE, M. (2000) What little girls are made of. The Observer $3^{\text {rd }}$ December p.18-31 (Life magazine).

SCHOR, J. (2004) Born to Buy: The Commercialized Child and the New Consumer Culture . New York: Scribner

SEITER, E. (1993) Sold separately: parents and children in consumer culture. New Brunswick, New Jersey: Rutgers University Press.

SMITH, R. (2000) "The contradictions of childhood." Children \& Society 14 (1)

p.3-10. 
SOCIAL TRENDS, (2005) Office for National Statistics . London: HMSO.

STEWART, F. (1992) The adolescent as Consumer. Youth Policy in the 1990s: the way forward. J. Coleman and C. Warren-Adamson (Eds.) London: Routledge.

THOMSON, R. et al. (2000) Researching childhood: time, memory and method . Paper presented BSA Annual Conference 'Making Time/ Marking Time. University of York. 